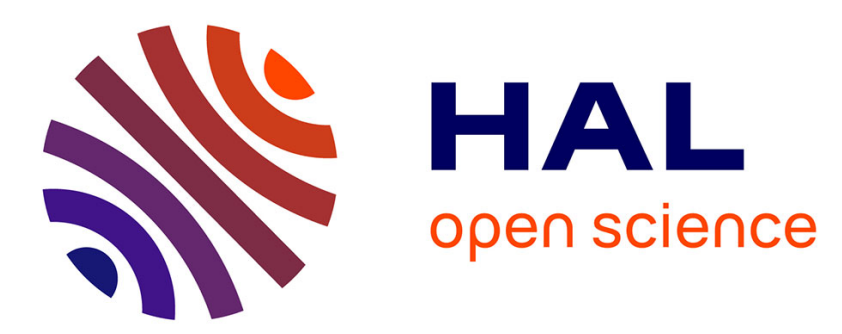

\title{
High temperature properties of AlN coatings deposited by chemical vapor deposition for solar central receivers
}

D. Chen, J. Colas, Michel Pons, Frédéric Mercier, R. Boichot, L. Charpentier, C. Escape, M. Balat-Pichelin

\section{- To cite this version:}

D. Chen, J. Colas, Michel Pons, Frédéric Mercier, R. Boichot, et al.. High temperature properties of AlN coatings deposited by chemical vapor deposition for solar central receivers. Surface and Coatings Technology, 2019, 377, pp.124872. 10.1016/j.surfcoat.2019.07.083 . hal-02906185

\section{HAL Id: hal-02906185 \\ https://hal.science/hal-02906185}

Submitted on 13 Nov 2020

HAL is a multi-disciplinary open access archive for the deposit and dissemination of scientific research documents, whether they are published or not. The documents may come from teaching and research institutions in France or abroad, or from public or private research centers.
L'archive ouverte pluridisciplinaire HAL, est destinée au dépôt et à la diffusion de documents scientifiques de niveau recherche, publiés ou non, émanant des établissements d'enseignement et de recherche français ou étrangers, des laboratoires publics ou privés. 
Danying Chen, Johann Colas, Frédéric Mercier, Raphaël Boichot, Ludovic Charpentier, et al.. High temperature properties of AIN coatings deposited by chemical vapor deposition for solar central receivers. Surface and Coatings Technology, Elsevier, 2019, 377, pp.124872.

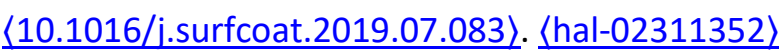

\title{
High temperature properties of AIN coatings deposited by chemical vapor deposition
}

\author{
D. Chen ${ }^{1}$, J. Colas ${ }^{2}$, M. Pons ${ }^{1}$, F. Mercier ${ }^{1}$, R. Boichot ${ }^{1}$, L. Charpentier ${ }^{2}$, C. Escape ${ }^{2}$, M. Balat-Pichelin ${ }^{2}$ \\ ${ }^{1}$ Université Grenoble-Alpes, SIMAP, Grenoble INP, CNRS, 38000 Grenoble, France \\ ${ }^{2}$ PROMES-CNRS, 7 rue du four solaire, 66120 Font-Romeu Odeillo, France
}

\begin{abstract}
There is an increasing interest for tower concentrated solar power (CSP) systems which can work at temperatures higher than $1073 \mathrm{~K}$ to optimize the efficiency. One of the challenges is to design the receiver that will be heated at high temperatures. On the contrary to coatings in gas turbine engine, the coating/substrate system must have a high thermal conductivity to ensure a good heat transfer to the fluid. Aluminum nitride (AIN) coating, deposited by chemical vapor deposition at $1373 \mathrm{~K}$ at a growth rate of 10-50 $\mu \mathrm{m} \mathrm{h}^{-1}$, was selected for its high thermal conductivity, low thermal expansion coefficient, high temperature stability and its ability to develop stable alumina scales above $1273 \mathrm{~K}$. Cast and ODS (Oxide Dispersion Strengthened) FeCrAl alloys, also alumina-formers, were chosen as model substrates to reduce the influencing parameters in real-life receivers and to study the potential of these coatings. Accelerated cyclic oxidation tests and emissivity measurements allowed the evaluation of AIN coatings as materials for high temperature CSP receivers. The multilayered systems showed low degradation after hundreds of thermal cycles at $1073 \mathrm{~K}$ in air and can support higher temperatures (1373 K) for 100 to $500 \mathrm{~h}$ depending on the coating thickness. Nevertheless the fast cyclic oxidations in solar furnace generated cracks through the coatings. The measurement of the optical properties also revealed a decrease of the absorptivity after oxidation.
\end{abstract}

\section{Introduction}

In power tower concentrating solar power systems (CSP), a large number of sun-tracking mirrors, known as heliostats, focus sunlight onto a receiver at the top of a tall tower. A heat-transfer fluid heated in the receiver is used to heat a working fluid, which, in turn, is used in a conventional turbine generator to produce electricity [1]. The challenge for a solar tower technology is related to ensuring the longevity of the receiver and demonstrating that the receiver material can handle high temperature fluxes across the 25-year lifespan of a plant. A further research step for this technology is to reach even higher temperatures $(1273 \mathrm{~K})$ and therefore higher efficiencies. The question of which material is the most suitable for different temperatures is still under study [2]. Receivers working with air as the heat transfer fluid (HTF) can simplify the technology but the challenges, like absorber durability, receiver efficiency still remains to be solved. It can generally be said that for temperatures below $1073 \mathrm{~K}$, nickel-based alloys with high chromium content are the most suitable for volumetric receivers due to their capacity to form oxides, which are black and highly absorbant [1]. The state-ofthe-art for solar absorbing materials used in solar towers, with air as HTF, is based on a commercially available black paint called Pyromark 2500s [3]. It is known to have a high thermal efficiency above $900 \mathrm{~K}$ [4]. However, according to prior studies, the absorptivity degraded after high temperature ( $>1000 \mathrm{~K}$ ) exposure due to crystal structure changes and phase instability [3]. Therefore it is clear that 
a new light absorbing coating material with a high absorption efficiency and an excellent durability at elevated temperature in air environment needs to be developed for the next generation CSP systems.

For temperatures above $1073 \mathrm{~K}$, the most suitable materials are dense or foam ceramics. Temperatures as high as $1500 \mathrm{~K}$ are achievable with Si-SiC ceramics and $1800 \mathrm{~K}$ with SiC ceramics [5]. $\mathrm{Al}_{2} \mathrm{O}_{3}$ ceramics, with a melting point of around $2300 \mathrm{~K}$ may also be used. Their main disadvantage is that they are white with poor optical properties but they can be doped to increase their absorptivity retaining good mechanical properties [5]. Other non-oxide ceramics like SiC foams and composites have better optical properties and absorptivity than oxides [6]. Recently, it was also demonstrated that cuprous bi-metallic spinel coatings are favorable candidates for CSP systems with air as HTF at $1023 \mathrm{~K}$ [7]. In order to reach a high efficiency, a solar receiver should have a high thermal conductivity, a high solar absorptivity, and a high resistance to thermal fatigue. Characterization of thermal losses and incident fluxes for a thermal receiver will lead to optimized receiver designs [8]. To achieve outlet temperatures of $1273 \mathrm{~K}$ new developments are necessary [9].

The scope of the present activity is a fundamental research on materials to be employed in thermal solar energy plants as solar receivers for temperatures higher than $1073 \mathrm{~K}$ and air as THF. Ideal candidate materials should possess a combination of properties such as $[2,10]$.

1. Selective absorption of the sun spectrum

2. Reduced emissivity at high temperature in the IR

3. High thermal conductivity

4. High temperature chemical stability

5. Low thermal expansion

6. Low creep during thermal cycling

7. High resistance to oxidation

It is difficult or impossible to fulfill all these conflicting properties with a single material. In this study, the research route is to develop ceramic coatings deposited on high temperature alloys. Aluminum nitride coating, deposited by chemical vapor deposition at $1373 \mathrm{~K}$ was selected for its high thermal conductivity, low thermal expansion coefficient, high temperature stability and its ability to develop stable alumina scales at high temperature [11]. $\mathrm{Al}_{2} \mathrm{O}_{3}$ layer which is formed during high temperature air exposure can modify underlying substrate properties [12-15] [11, 16-17]. Along with low fabrication costs, these coatings also present self-healing effects if the protective surface oxide layer fails [18]. For the substrate, fast-creeping cast FeCrAl alloy (Fecralloy-Goodfelow Metals) and slow creeping oxide dispersion strengthened FeCrAl (Kanthal APMT-Sandvik) were chosen. As recently published by Seiler et al. [19], the choice of these alumina-forming alloys allows a simplification of the complex problem of the system lifetime since this class of alloys has a superior oxidation resistance up to $1500 \mathrm{~K}$. Thus, it is possible to characterize optical, mechanical and chemical properties of coatings at high temperatures (1073-1500 K). Their outstanding resistance to oxidation is based on their ability to form a very slow growing and protective alumina scale during service [20-23] [24-25]. However, the relatively low mechanical strength of these ferritic alloys at elevated temperatures strongly limits their application in mechanically stressed components or in cyclic temperature conditions. It was shown that minor additions of oxygen active elements (less than $1 \mathrm{wt} \%$ ), especially yttrium, either as a metallic addition ( $\mathrm{Y}, \mathrm{La}, \mathrm{Ce}, \mathrm{Zr}, \mathrm{Hf})$ or as oxide dispersion $\left.\mathrm{Y}_{2} \mathrm{O}_{3}\right)$, improve the oxide growth rate and its resistance to spallation [21]. Kanthal APMT (Fe-22Cr-5.Al-3Mo and oxide inclusions) further improved hot strength and retained alumina protection up to $1600 \mathrm{~K}$ [23]. APMT combine the excellent oxidation resistance of cast FeCrAl alloys with a sufficiently high creep resistance for moderately loaded 
components at high temperature (1000-1273 K). At these high temperature Ni-base alloys degrade rapidly because $\mathrm{Cr}_{2} \mathrm{O}_{3}$ scale are non-protective above $1073 \mathrm{~K}$ [25] rapidly forming iron oxides [26].

The comparison of coated and uncoated systems will allow the quality of the coating to be studied. In addition, the thermal fatigue of these systems can be evaluated during cyclic oxidation tests of the coatings deposited on the two alloy classes. Accelerated cyclic oxidation tests and emissivity measurements are made solar furnace facilities [27] to study the potential of AIN coatings as materials for high temperature CSP receivers.

\section{Materials and methods}

\section{Substrates}

The first substrate is a Cast FeCrAl alloy (Fecralloy Goodfellow metal) that consists of 22 wt\% Cr, 5 wt\% Al, 0.1 wt\% Y, 0.1 wt\% $\mathrm{Zr}$ and Fe (balance). The second substrate, Kanthal APMT (Sandvik, Kanthal) is an oxide dispersion strengthened (ODS) material with a slow creeping rate. Its composition is $22 \mathrm{wt} \%$ $\mathrm{Cr}, 5 \mathrm{wt} \% \mathrm{Al}, 3 \mathrm{wt} \% \mathrm{Mo}$ and Fe (balance). In the analysis below, it is convenient to denote the cast and ODS FeCrAl alloys used in this work by Fecralloy and APMT respectively.

By analyzing AIN coatings deposited on these model materials, failure mechanisms in the coatings and the influence of creep rate can be studied without the complicating influence of ongoing substrate oxidation as well in experiments as in modeling.

\section{CVD experiments}

AIN films were grown by high temperature chemical vapor deposition (HT-CVD). Prior to the HT-CVD process, cast FeCrAl and APMT were cut into small specimens with dimensions of approximately 15 $\times 15 \times 2 \mathrm{~mm}$ and $15 \times 15 \times 3 \mathrm{~mm}$ respectively. Before loading into the CVD reactor, these substrates were hand-polished with 320 grit SiC paper, and then ultrasonically cleaned for 5 minutes in acetone, ethanol and isopropanol successively.

The HT-CVD set-up consists of a graphite susceptor heated by induction in a vertical cold-wall reactor. The reactants used are ammonia $\mathrm{NH}_{3}(99.999 \%)$ and aluminum chlorides $\mathrm{AlCl}_{\mathrm{x}}$ in situ formed via chlorination of high purity Al pellets (99.999\%) with chlorine gas $\mathrm{Cl}_{2}(99.999 \%)$ at $800 \mathrm{~K}^{\circ} \mathrm{H}_{2}(99.999 \%)$ is used as carrier gas. The details of the process and its modeling can be found in previous studies [2832]. The total pressure inside the reactor was set to $2000 \mathrm{~Pa}$. The deposition temperature is fixed at $1373 \mathrm{~K}$ and was measured inside the susceptor using a thermocouple or by an IR pyrometer. Prior to deposition, a thermal cleaning under $\mathrm{H}_{2}$ atmosphere was carried out at $1373 \mathrm{~K}$ for $10 \mathrm{~min}$. The N/Al ratio is defined as the $\mathrm{NH}_{3} / \mathrm{AlCl}_{3}$ ratio and is varied from 1.33 to 20 by keeping $\mathrm{Cl}_{2}$ flow rate at $20 \mathrm{sccm}$ and varying the $\mathrm{NH}_{3}$ flow rate from 40 to $600 \mathrm{sccm}$. We assume that the chlorination reaction yield is 1 and that the $\mathrm{AlCl}_{3}$ is the dominant gaseous species in these conditions [30].

The high creep resistance of APMT together with the large difference of thermal expansion coefficient between APMT $\left(\sim 15.4 \times 10^{-6} \mathrm{~K}^{-1}\right)$ and AIN $\left(\sim 4.2 \times 10^{-6} \mathrm{~K}^{-1}\right)$ lead to the cracking of AIN films after deposition. To avoid the cracking, an accommodation layer of $\mathrm{Al}_{2} \mathrm{O}_{3}\left(\sim 8.4 \times 10^{-6} \mathrm{~K}^{-1}\right)$ was grown prior to AIN deposition by oxidizing APMT substrates at $1373 \mathrm{~K}$ under ambient air during $25 \mathrm{~h}$.

The surface morphology of polycrystalline AIN layers was characterized by field emission scanning electron microscopy (FE-SEM). The crystal structure and the orientation of the films were identified by electron backscattered diffraction (EBSD) and X-ray diffraction (XRD) analysis using a X'PERT PRO MPD PANalytical 2-circles diffractometer (Cu Ka radiation $(\lambda=1.54 \AA$ ) , $\theta-\theta$ ).

\section{Experimetal set-up for high temperature oxidation}

Uncoated samples were ground to a 1200 grit surface finish. Prior to oxidation, all samples were ultrasonically cleaned. Cyclic oxidations of AIN coated samples were carried out in the $1073 \mathrm{~K}-1273 \mathrm{~K}$ temperature range in air at ambient pressure in a Nabertherm P310 tube furnace equipped with a 99.7\% purity alumina tube. The furnace power was controlled by feedback from a S-type thermocouple 
placed near the sample. To evaluate the oxidation performance of AIN coatings, uncoated samples were also oxidized at $1373 \mathrm{~K}$ in same conditions. After each oxidation cycle, samples were taken out from the furnace and cooled down to room temperature in air. The weight changes of oxidized samples were measured by a laboratory digital balance with a precision of $0.001 \mathrm{~g}$. The surface morphology and microstructure of oxide layers were subsequently investigated by FE-SEM.

PROMES laboratory has developed several experimental reactors to study high-temperature materials under solar radiation. Among them, the REHPTS set-up (Figure 1) is a reactor implemented at the focus of the $6 \mathrm{~kW}$ vertical solar furnace in order to study materials under extreme coupled conditions (corrosive atmosphere and high temperature) [33]. The REHPTS set-up has been used in open air at atmospheric pressure of $0.87 \times 10^{5} \mathrm{~Pa}$ as the laboratory is located at $1500 \mathrm{~m}$ altitude. A servo-controlled flat mirror (named heliostat) reflects the incoming solar flux toward a facetted hemispherical concentrator, and the sample is placed $25 \mathrm{~mm}$ above the focus of the solar furnace, thus elevated temperatures on materials may be obtained at very fast rate (up to $100 \mathrm{~K} \cdot \mathrm{s}^{-1}$ ) on a homogeneous $1 \mathrm{~cm}$ diameter area. The temperature is measured using an optical pyrometer (at $\lambda=5 \mu \mathrm{m}$ ) and can be controlled by the opening angle of the shutter, determining the fraction of the concentrated solar flux that is transmitted to the sample.

\section{Optical properties at room temperature}

The hemispherical reflectivity at $300 \mathrm{~K}$ was measured with a Perkin Elmer HDR 950 for the range 0.25 and $2 \mu \mathrm{m}$ and with a SOC $100 \mathrm{HDR}$ for the range 2 to $25 \mu \mathrm{m}$. All samples are considered as opaque, consequently the spectral hemispherical emissivity $(\varepsilon)$ is assumed as related with the spectral hemispherical reflectivity $(\rho)$ by the following relation ( $\lambda$ is the wavelength):

$$
\varepsilon(\lambda)=1-\rho(\lambda)
$$

Solar absorptivity, $\alpha_{\text {sol }}$, is calculated from the measured spectral hemispherical emissivity, $\varepsilon(\lambda)$, and the spectral solar irradiance AM1.5 contained in the range 0.25 and $2.5 \mu \mathrm{m}$ [34]. Total emissivity, $\varepsilon_{\text {tot, }}$, is obtained from the measured spectral hemispherical emissivity and the calculated spectral blackbody emittance at $300 \mathrm{~K}, \mathrm{E}_{\mathrm{bb}}(\lambda, 300 \mathrm{~K})$, according to Planck's law. The integration for total emissivity is between 0.25 and $25 \mu \mathrm{m}$ in accordance with the reflectivity measurement.

$$
\begin{gathered}
\alpha_{s o l}=\frac{\int_{0.25}^{2.5} \varepsilon(\lambda) \cdot I_{\text {sol }}(\lambda) \cdot d \lambda}{\int_{0.25}^{2.5} I_{\text {sol }}(\lambda) \cdot d \lambda} \\
\varepsilon_{t o t}=\frac{\int_{0.25}^{25} \varepsilon(\lambda) \cdot E_{b b}(\lambda, 300 K) \cdot d \lambda}{\int_{0.25}^{25} E_{b b}(\lambda, 300 K) \cdot d \lambda}
\end{gathered}
$$

\section{RESULTS AND DISCUSSION}

\section{AIN deposition}

Our previous studies of AIN deposition by high temperature CVD have been made in a large temperature, pressure and flow range of precursors [28-32]. It was shown that the surface morphologies are sphere-like (1073 K) and become plate-like for temperatures above $1273 \mathrm{~K}$ [30, 32, 35]. At these high temperatures, the surface diffusion of chemical species is enhanced and leads to the formation of 1-3 $\mu \mathrm{m}$ size facetted grains. It was shown also that low N/Al ratio are preferable to have dense layers at temperatures above $1273 \mathrm{~K}$. From the present study, we observe an increase of the grain size when the N/Al decreases (Figure 2 (a)-(e)) due to a decrease of supersaturation [32]. Additionally, we observe dense layers only for $\mathrm{N} / \mathrm{Al}=1.33$, as observed in our previous studies. 

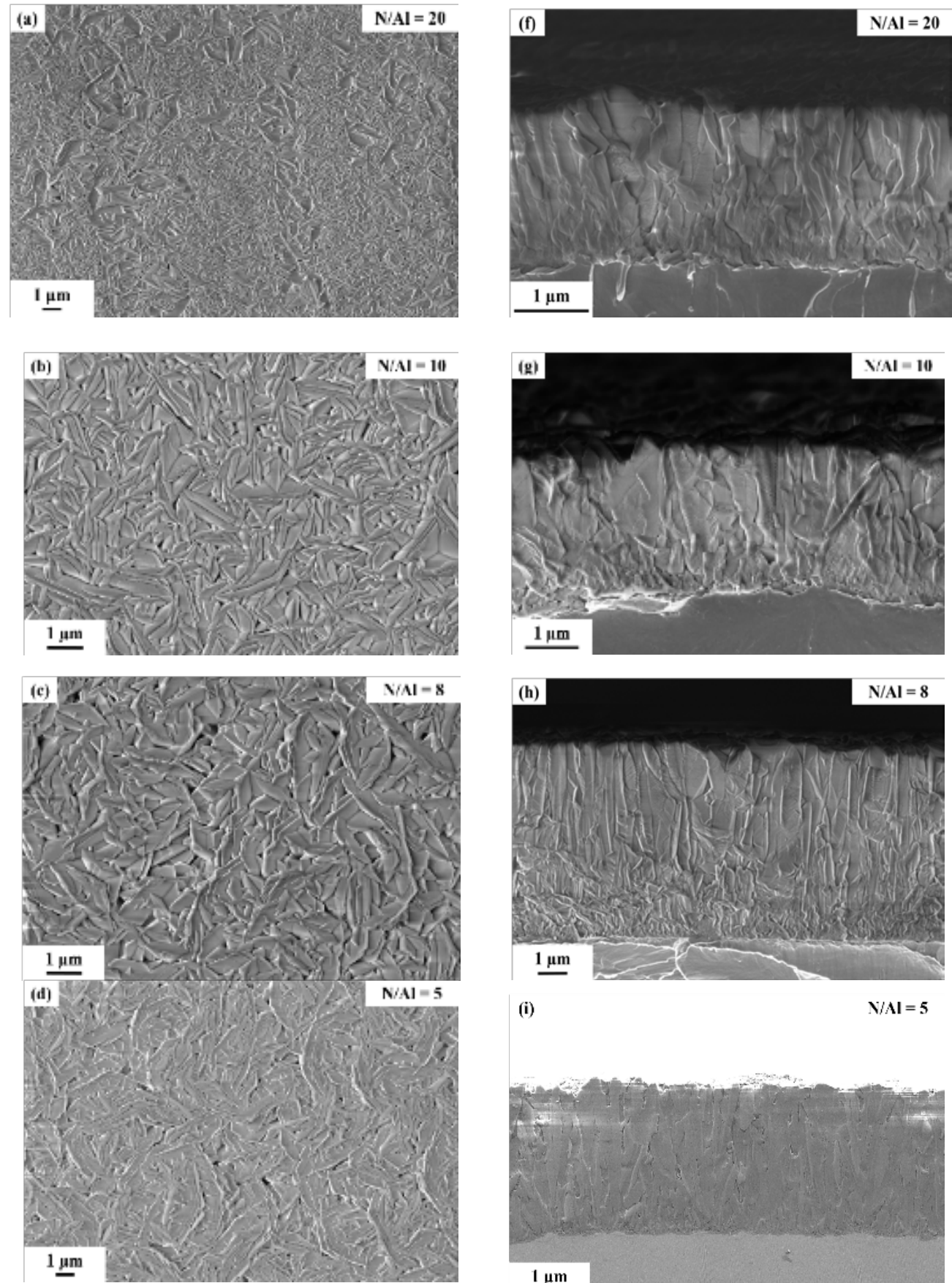

(i)

$\mathbf{N} / \mathbf{A} \mathbf{I}=\mathbf{5}$
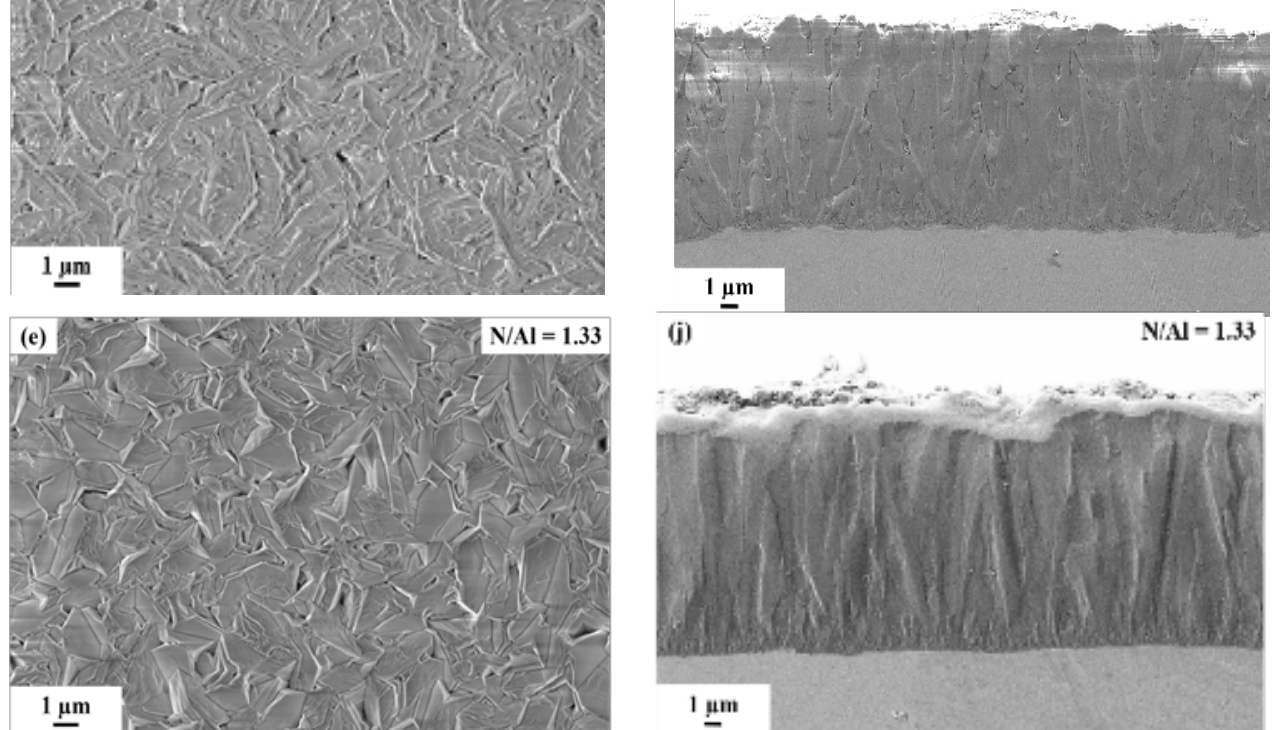

(j)

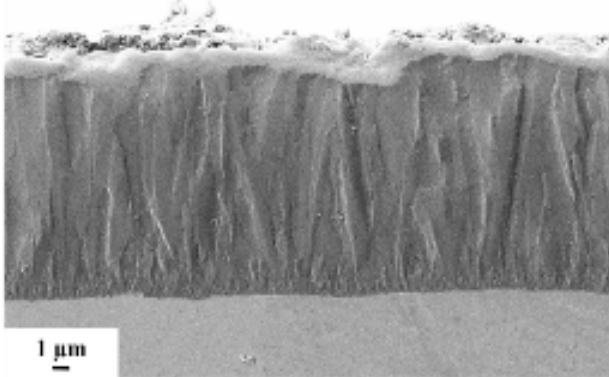

Figure 2: Surface morphologies and cross-sections of AIN coating processed on Fecralloy at $\mathrm{T}=1373 \mathrm{~K}$, $\mathrm{P}=2000 \mathrm{~Pa}, \mathrm{Cl}_{2}$ flow rate of $20 \mathrm{sccm}, \mathrm{NH}_{3}$ flow rate varying from 40 to $600 \mathrm{sccm}, \mathrm{N} / \mathrm{Al}$ ratio estimated by $\mathrm{NH}_{3} / \mathrm{AlCl}_{3}$ inlet flow rates ratio assuming that $\mathrm{AlCl}_{3}$ is the predominant $\mathrm{AlCl}$ species. 
The preferential orientation strongly depends on process parameters, N/Al ratio in gas phase, deposition temperature, partial pressure of each precursor, etc. Herein, cross-sections (Figure 2 (f)-(j)) were performed to characterize the evolution of grain size and texture from the AIN/substrate interface as a function of the N/AI ratio. All deposited AIN coatings exhibit a columnar structure resulting from the competition between different crystalline orientations. Grain size increases from the AIN/substrate interface to the surface. The small grains at the AIN/substrate interface are the results of random nucleation at the beginning of the growth. At high degree of supersaturation, i.e. $\mathrm{N} / \mathrm{Al} \geq 5$, immobile grain boundaries are formed through coalescence of initial small islands with large surface to volume ratios. Subsequent grain coarsening occurs through epitaxial growth on these grains. The competitive growth processes lead to the incomplete orientation selection, and thus weakly textured grains.
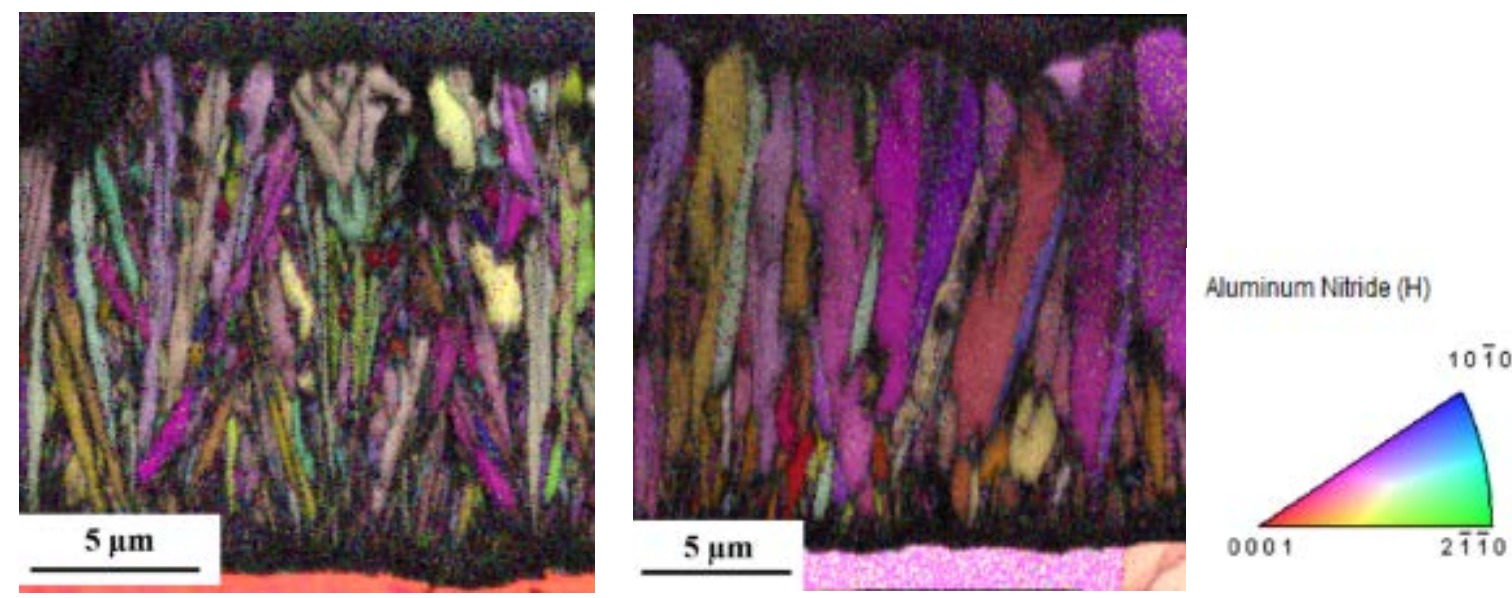

Figure 3. EBSD image quality figures of as coated systems shown in Figure 2: (a) N/Al=5 and (b) $\mathrm{N} / \mathrm{Al}=1.33$.

The EBSD maps of AIN thin films processed with N/Al ratio of 1.33 and 5 are shown in Figure 3 . It is worth noting that the AIN film deposited at low supersaturation (N/AI=1.33) exhibit some preferential orientations. Grains are grown with a rotation about c-axis, while the (h00) orientations are disfavored, showing good agreement with XRD measurements (not given here). The AIN coating grown with a high supersaturation ( $\mathrm{N} / \mathrm{Al}=5)$ does not present such texture and grains are more disordered.

\section{High temperature Oxidation}

\section{Oxidation kinetics and scale microstructure}

For uncoated samples, the oxidation reaction of Fecralloy and APMT is written as:

$$
\mathrm{Al}+\frac{3}{2} \mathrm{O}_{2} \rightarrow \mathrm{Al}_{2} \mathrm{O}_{3}
$$

The corresponding thickness of the scale can be estimated using:

$$
e=\frac{2 M_{A l_{2} O_{3}}}{3 M_{O_{2}} \rho_{A l_{2} O_{3}}} \frac{\Delta m}{S}
$$

Where: $M_{A l 2 O 3}$ is the molecular weight of $\mathrm{Al}_{2} \mathrm{O}_{3}, M_{O}$ the molecular weight of oxygen, $\rho_{A l 203}$ the density of $\alpha-\mathrm{Al}_{2} \mathrm{O}_{3}\left(3.97 \mathrm{~g} \mathrm{~cm}^{-3}\right), \frac{\Delta m}{S}$ is the mass gain divided by the surface area of the oxidized sample.

Fecralloy and APMT are known for their excellent resistance to high temperature oxidation forming dense and adherent alumina scales [20-23] [24-25]. Experiments made by $\mathrm{O}^{18}$ tracer distribution in the 
alumina scale have indicated short-circuit diffusion of oxygen as the driving force of oxidation [39]. The scale thickness theoretically increases as a function of the square root of time exposure. In reality, the growth rate is lower due to material changes with time and the impact of creep and thermal cycling (Table 1). The growth mechanism is driven by grain boundary oxygen diffusion in combination with competitive growth of columnar alumina grains [21]. The a values and kinetic constants are in the same range as those encountered in the literature [20-23] [24-25]. The a-values of about 0.33 are typical of modifications of pure diffusion limiting growth $(a=0.5)$ by structural and stress evolution.

Table 1: Kinetic laws for the oxidation of substrates at $1373 \mathrm{~K}$.

$\frac{\Delta m}{S}=k t^{a}, \mathrm{~K}$ is the kinetic constant $\left(\mathrm{mg} \cdot \mathrm{cm}^{-2} \mathrm{~h}^{-a}\right)$, a the exponent of time $(\mathrm{t})$ and $\frac{\Delta m}{S}$ is the mass gain in $\mathrm{mg} \cdot \mathrm{cm}^{-2}$

\begin{tabular}{|l|l|l|}
\hline Sample name & $\mathbf{k}\left(\mathbf{m g} \cdot \mathbf{c m}^{-\mathbf{2}} \mathbf{h}^{-\mathbf{a}}\right)$ & $\mathbf{a}$ \\
\hline Uncoated Fecralloy & 0.1088 & 0.3818 \\
\hline Uncoated APMT & 0.1184 & 0.3337 \\
\hline
\end{tabular}

For AIN coated samples, the oxidation of AIN is a solid-gas reaction involving the exchange of oxygen and nitrogen:

$$
2 \mathrm{AlN}+\frac{3}{2} \mathrm{O}_{2} \rightarrow \mathrm{Al}_{2} \mathrm{O}_{3}+\mathrm{N}_{2}
$$

The thickness of the scale was evaluated taking into account nitrogen liberation using:

$$
\begin{aligned}
& \frac{\Delta m^{\prime}}{S}=\frac{\Delta m}{S}-\frac{\Delta m_{N_{2}}}{S} \\
& e=\frac{2 M_{A l_{2} O_{3}}}{3 M_{O_{2}} \rho_{A l_{2} O_{3}}} \frac{\Delta m^{\prime}}{S}
\end{aligned}
$$

For AIN coated samples, the mass gain is small in the low temperature range (1073 K- $1173 \mathrm{~K}$ ), less than $1 \mathrm{mg} \mathrm{cm}^{-2}$ after $1000 \mathrm{~h}$ of oxidation. In this temperature range, the surface is not fully covered by the oxide layer. The oxidation process proceeds linearly and is governed by the surface area of the unreacted AIN. From XRD, only $\theta$ - and $\gamma$-alumina are detected. The mass gain abruptly increases at $1273 \mathrm{~K}$ in agreement with previous results [37-38]. At $1373 \mathrm{~K}$, the mass gains remain small, about 1.5 to $2 \mathrm{mg} \cdot \mathrm{cm}^{-2}$ after $1500 \mathrm{~h}$ of oxidation (Figure 4). These mass gains correspond to an average scale thickness of 30-40 $\mu \mathrm{m}$ considering a $100 \%$ dense $\alpha$-alumina scale (the only oxide detected by XRD). Mass gains are relatively high during the first hours and then slow down. 


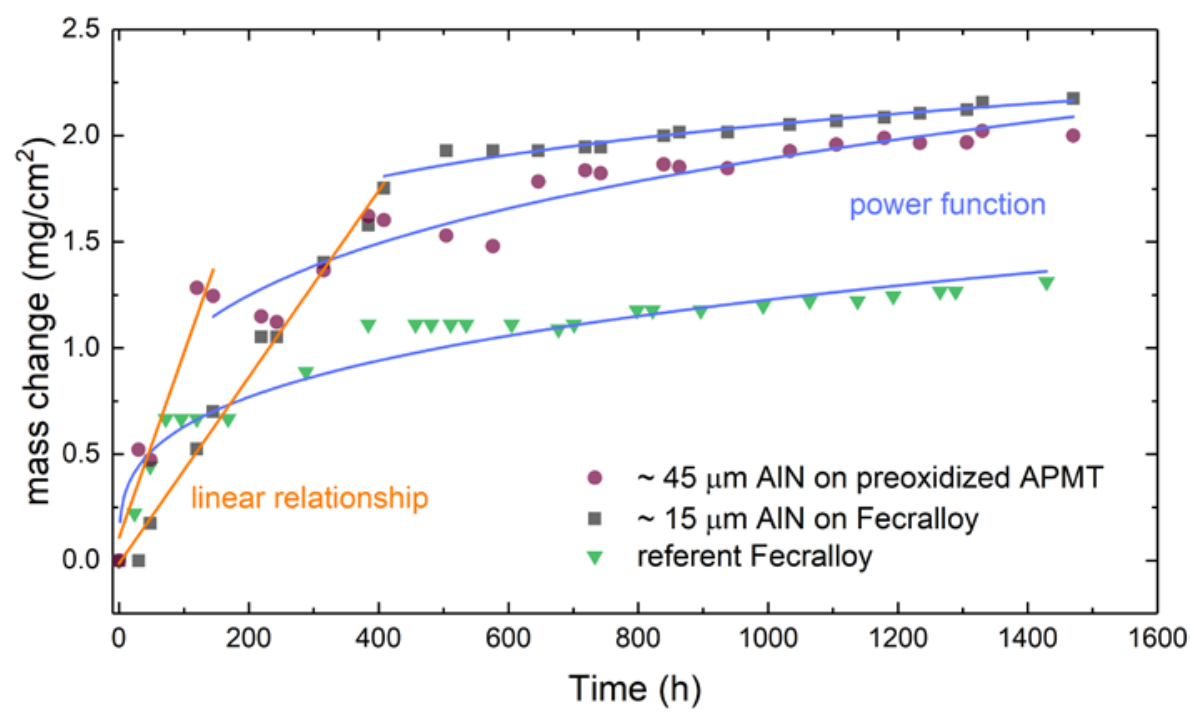

Figure 4: High temperature oxidation at $1373 \mathrm{~K}$ at atmospheric air pressure

There are few data concerning the oxidation of AIN coatings or thin films [15, 17, 40-43]. We expect that AIN plays two roles firstly as an oxygen sink that reacts to alumina and secondly as a better absorbing layer than metallic alloys. As a function of the adherence of the coating and of the oxide scale, the lifetime of different class of alloys could be extended owing to the aluminum reservoir. The two limiting steps of the oxidation mechanism are (i) the gas diffusion through the oxide layer to the surface of the nitride film and (ii) nucleus formation and chemical reaction to form the oxide layer. Same observations also exist in the oxidation of other nitride materials [44]. At 1073 and $1373 \mathrm{~K}$, at the beginning of oxidation, kinetics is linear indicating that the limiting phenomena are surface reactions. The activation energy of the linear regime is close to $150 \mathrm{~kJ} \mathrm{~mol}^{-1}$. The kinetic law is:

$$
\frac{\Delta m}{S}=k_{0} \exp \left(-\frac{E_{a}}{R T}\right) t^{a}
$$

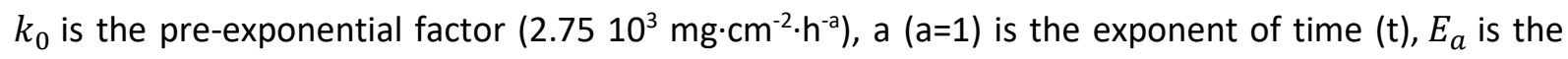
activation energy $\left(150 \mathrm{~kJ} \cdot \mathrm{mol}^{-1}\right), T$ the temperature $(K)$ and $\frac{\Delta m}{S}$ is the mass gain in $\mathrm{mg} \cdot \mathrm{cm}^{-2}$. The duration of the linear regime is proportional to the thickness of the AlN layer, $150 \mathrm{~h}$ for the $15 \mu \mathrm{m}$ layer and $500 \mathrm{~h}$ for the $45 \mu \mathrm{m}$ layer at $1373 \mathrm{~K}$ (Figure 4). For lower temperatures, the regime remains linear for longer times suggesting that the AIN layer is not completely oxidized. Then, the order of the reaction increases suggesting that the oxidation is driven by diffusion limited growth and alumina grain growth as for alloy substrates.

There is no delamination of oxide scales, nor cracks on both coated and uncoated samples. However, the microstructure of oxide scales is different. On uncoated substrates, the oxide scale is columnar with a grain size of about $1 \mu \mathrm{m}$. This result is in agreement with literature data compiled by Smialek et al. [46]. The diffusion of $\mathrm{Al}^{3+}$ cations and $\mathrm{O}^{2-}$ anions through the lattice and grain boundaries in aluminum oxide is very low, $10^{-19}$ and $10^{-22} \mathrm{~m}^{2} \cdot \mathrm{s}^{-1}$ respectively at $1373 \mathrm{~K} \mathrm{[11]}$. It suggests that the diffusion length should be of some tens of nanometers and the oxide layer reaches a value of some $\mu \mathrm{m}$ after $94 \mathrm{~h}$ oxidation at $1373 \mathrm{~K}$. For AIN coated samples, many small pores are found within the oxidized layer. The size of the pores varies from 20 to $500 \mathrm{~nm}$. These pores are observed for all the $\mathrm{N} / \mathrm{Al}$ investigated and cannot be related to the density of the layer. Figure 5 (b) shows a typical microstructure of the porous layer (here for $\mathrm{N} / \mathrm{Al}=5$ ). The reaction of AIN with air involves the release of nitrogen [11, 47-48]. In the first hours, the driving force for the oxidation of AIN is the formation of small pores which generate large fresh surface area leading to further reaction to take place. This is 
confirmed by the linear kinetics observed. The pores remain interconnected throughout the oxidation. Such microstructure enables the penetration of oxygen, leading to fast oxygen diffusion in AIN layer and rate-limiting reaction at the alumina/AIN interface. For longer times, the substrate is oxidized by oxygen diffusion through the porous layer and the oxidation proceeds as in substrates (Figure 6).
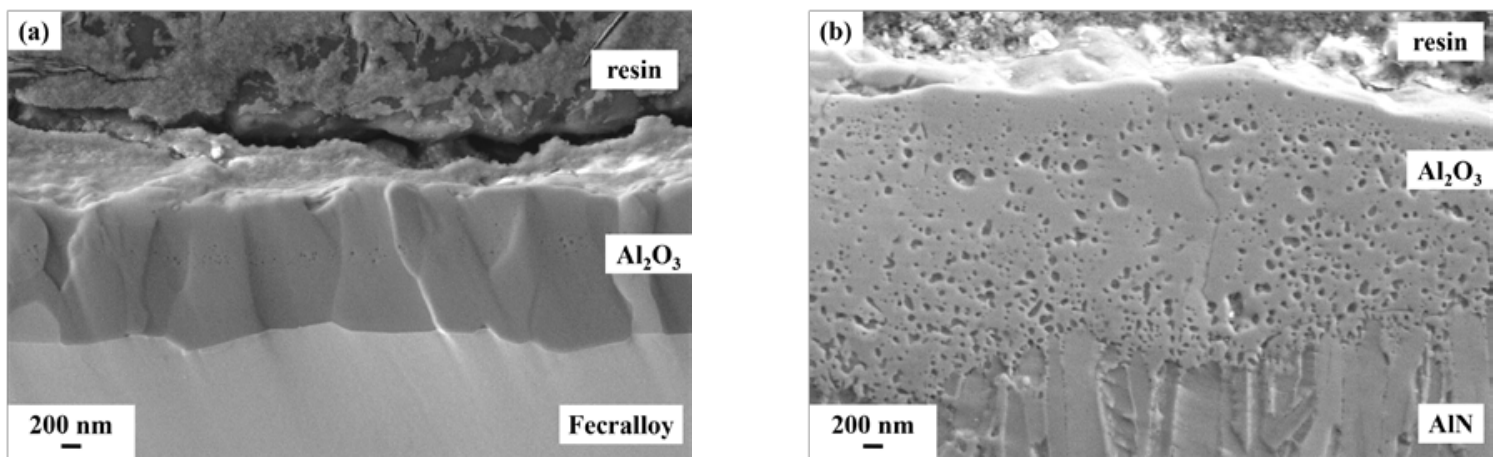

Figure 5: Cross-section after $94 \mathrm{~h}$ of oxidation at $1373 \mathrm{~K}$ of Fecralloy uncoated and coated with $10 \mu \mathrm{m}$ AIN (N/Al=5).

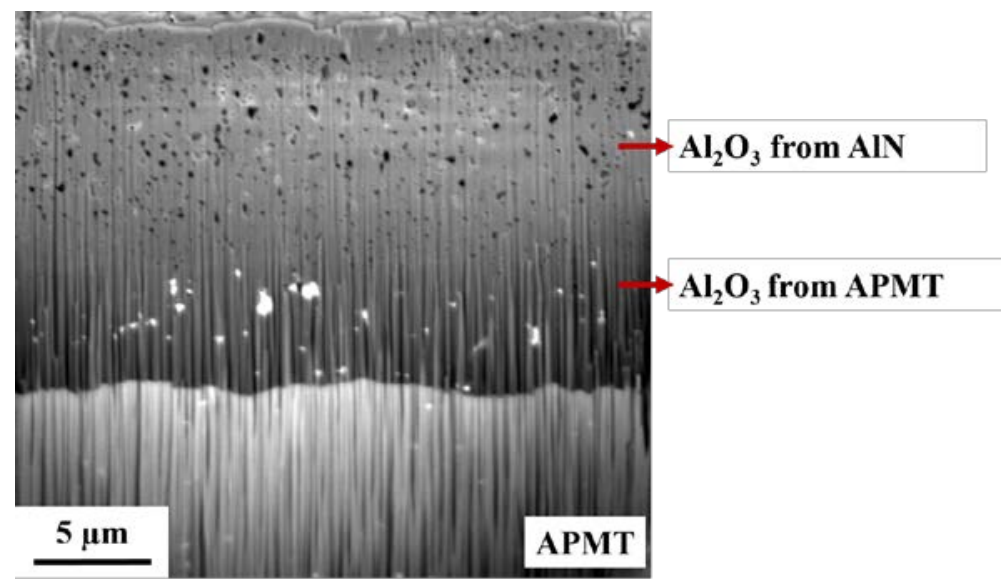

Figure 6: Cross-section after $1500 \mathrm{~h}$ of oxidation at $1373 \mathrm{~K}$ of pre-oxidized APMT coated with $15 \mu \mathrm{m}$ $\operatorname{AIN~(N/Al=1.33).~}$

To be close-to real conditions of CSP receivers, fast thermal cycling experiments of AIN coated samples were carried out using the REHPTS set-up. Samples were heated up to a temperature plateau during $20 \mathrm{~min}$, then cooled and weighted, during 4 consecutive cycles. The behaviors of Fecralloy and preoxidized APMT coated with 15 to $40 \mu \mathrm{m}$ of AIN are identical for the same conditions. Figure 7 presents the mass gain during the cyclic oxidation in open air of AIN-coated Fecralloy and APMT. 


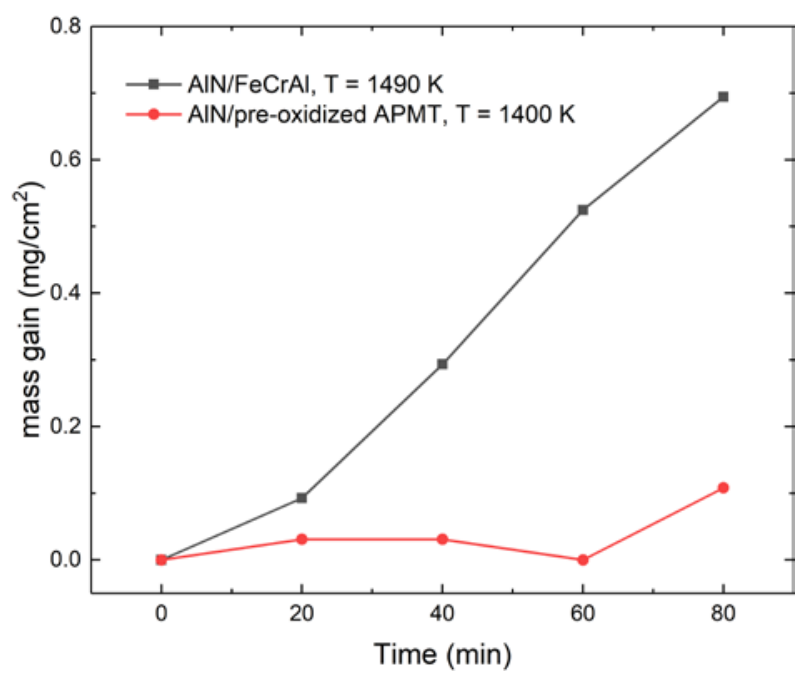

Figure 7: Mass gain during the cyclic oxidation in air of AlN-coating on Fecralloy at $1490 \mathrm{~K}$ and preoxidized APMT at $1400 \mathrm{~K}$.

Figure 8 presents the pictures of the 4 samples after cyclic oxidation. The samples do not present visible damages. However, microscopic cracks appear in the fast thermal cycling corresponding to real operating conditions (Figure 9).

(a)

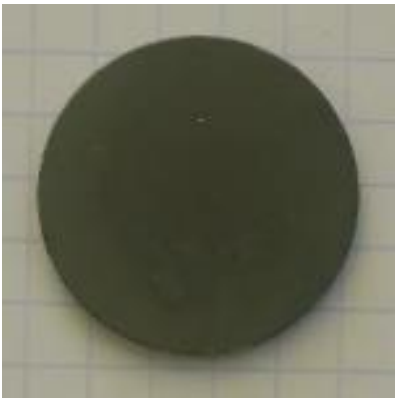

(c)

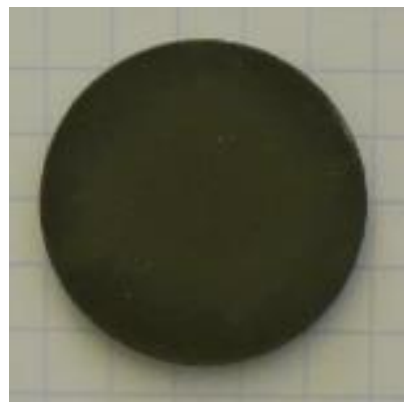

(b)

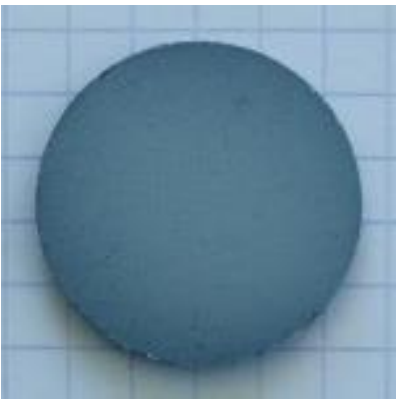

(d)

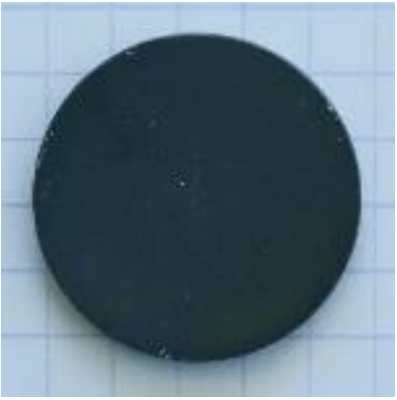

Figure 8: Macroscopic images of AIN/Fecralloy (a) before and (b) after 4 cycles at $1490 \mathrm{~K}$; AlN/preoxidized APMT (c) before and (d) after 4 cycles at $1400 \mathrm{~K}$. 

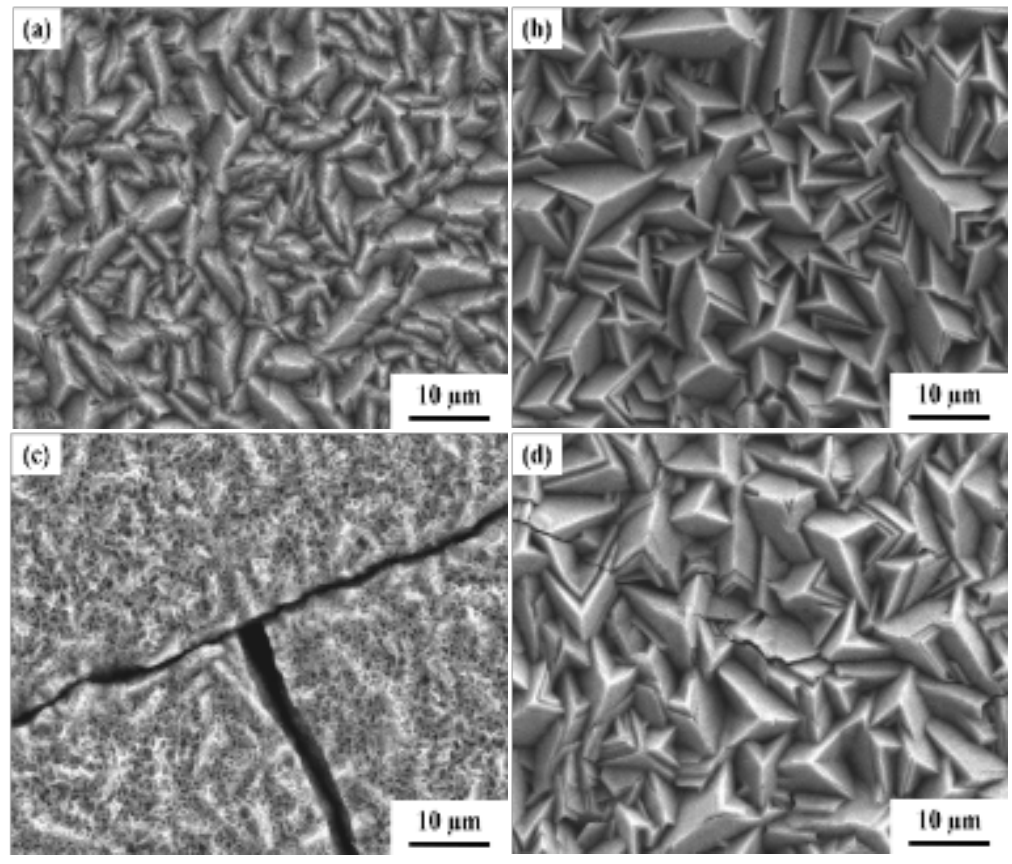

Figure 9: SEM images of of AIN/Fecralloy (a) before and (b) after 4 cycles at $1490 \mathrm{~K}$; AIN/pre-oxidized APMT (c) before and (d) after 4 cycles at $1400 \mathrm{~K}$.

\section{Lifetime evaluation}

The lifetime of uncoated alloys is a function of aluminum available in the alloy because $\mathrm{Al}$ is progressively depleted by the growing scale. The critical Al level, initially $5 \mathrm{wt} \%$, before oxidation failure occurs, strongly depends on cycling, creep and material dimensions [22-23]. Typically, at least $2 \mathrm{wt} \%$ of Al in the alloy is necessary to maintain the growth of a pure alumina iayer. For lower concentrations, iron and chromium oxides are formed at a high rate. It was shown that the studied FeCrAl alloys can withstand more than $10000 \mathrm{~h}$ before scale spallation and catastrophic oxidation [22-23].

The lifetime of AIN coatings is due to the thermally grown oxide with a good bonding strength and a low growth rate in the low temperature range (1073-1173 K). Moreover, there is a lower mismatch of thermal expansion of alumina $\left(8.3 \times 10^{-6} \mathrm{~K}^{-1}\right)$ and $\mathrm{AIN}\left(4.2 \times 10^{-6} \mathrm{~K}^{-1}\right)[49]$ in comparison with FeCrAl alloys $\left(15 \times 10^{-6} \mathrm{~K}^{-1}\right)$. The weak interface is the alloy/AIN interface and compressive stress develops during the cooling stage. However, the thickness of the oxide scale after oxidation at $1373 \mathrm{~K}$ for $1500 \mathrm{~h}$ is about $30 \mu \mathrm{m}$. This suggests that the scales do not reach the critical thickness for spallation and the alumina growth rate is the only lifetime limiting factor. It is, however, not known whether thermal cycling can lead to scale microcracking and consequently enhanced oxide growth rates and whether the scale, formed on the AIN coating becomes prone to spallation under severe cyclic conditions. It is also worth noting that the presence of water vapor can modify oxidation reactions, increase oxide growth rate and contribute to the formation of hydroxyl compounds [47].

We have shown that the oxidation of coatings composed of aluminum nitride follows linear kinetics in the $1073-1373 \mathrm{~K}$ temperature range. The oxidation rate is very slow below $1273 \mathrm{~K}$. The lifetime of a 15 $\mu \mathrm{m}$ coating can be estimated at $1073 \mathrm{~K}$ for a few years and $1373 \mathrm{~K}$ for a few hundred hours. For daily thermal cycle conditions, the oxide layers remain adherent even after consumption of the entire 
coating. For more severe conditions, cracking of the coating is observed from the first hours of oxidation but without delamination of the initial layer (except sometimes on the edges of the sample). It is difficult to conclude that this coating is effective under severe cyclic conditions close to $1373 \mathrm{~K}$. However, for working temperatures between 1073 and $1273 \mathrm{~K}$, the service life of this coating can reach several years. To finalize the evaluation of this coating for solar receivers, it is now necessary to study the absorptivity in the wavelength range of solar radiation.

\section{Optical properties}

Figure 10 presents the hemispherical spectral emissivity of Fecralloy and coated Fecralloy, before and after the cyclic oxidation conditions of Figure 7. Table 2 reports the values of the solar absorptivity, total emissivity and $\alpha / \varepsilon$ ratio calculated for these samples from the integrated values of spectral emissivity, using eq. (2) and (3).

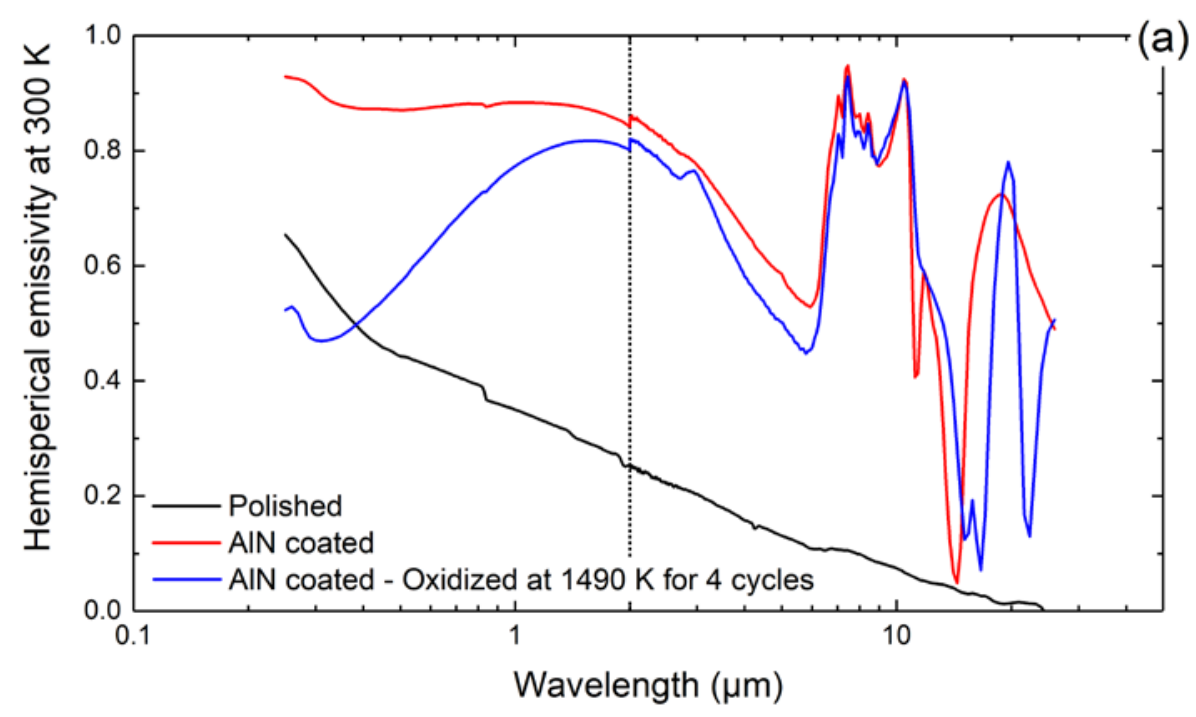

Figure 10: Hemispherical spectral emissivity of polished, AIN coated and oxidized Fecralloy ; the thickness of AlN layer is $40 \mu \mathrm{m}$.

Table 2: Calculated values (from eq. (2) and (3) ) of the solar absorptivity, total emissivity and $\alpha / \varepsilon$ ratio for the as-received Fecralloy and Fecralloy + AIN before and after cyclic oxidation,

\begin{tabular}{llll} 
& $\boldsymbol{\alpha}_{\text {sol }}$ & $\boldsymbol{\varepsilon}_{\text {tot }}$ & $\boldsymbol{\alpha} / \boldsymbol{\varepsilon}$ \\
\hline Fecralloy, as received & 0.39 & 0.05 & 7.0 \\
Fecralloy + AIN & 0.87 & 0.62 & 1.4 \\
Fecralloy + AIN, after cyclic oxidation at 1490 K & 0.68 & 0.57 & 1.2
\end{tabular}

We observe in figure 10 and Table 2 that the AIN coating improves the solar absorptivity of the Fecralloy substrate. In the same way, the coating also increases the total emissivity but it stays lower than the solar absorptivity as the $\alpha / \varepsilon$ ratio is higher than one. Nevertheless, the oxidation of the AIN coating tends to decrease the solar absorptivity.

Figure 11 presents the hemispherical spectral emissivity of APMT and APMT + AIN as received and after cyclic oxidation in the REHPTS set-up (conditions of Figure 7) and also after $100 \mathrm{~h}$ of oxidation in a conventional furnace (see Figure 5 for the microstructure of the studied sample). Table 3 reports the 
values of the solar absorptivity, total emissivity and $\alpha / \varepsilon$ ratio calculated for these samples from the integrated values of spectral emissivity, using eq. (2) and (3).

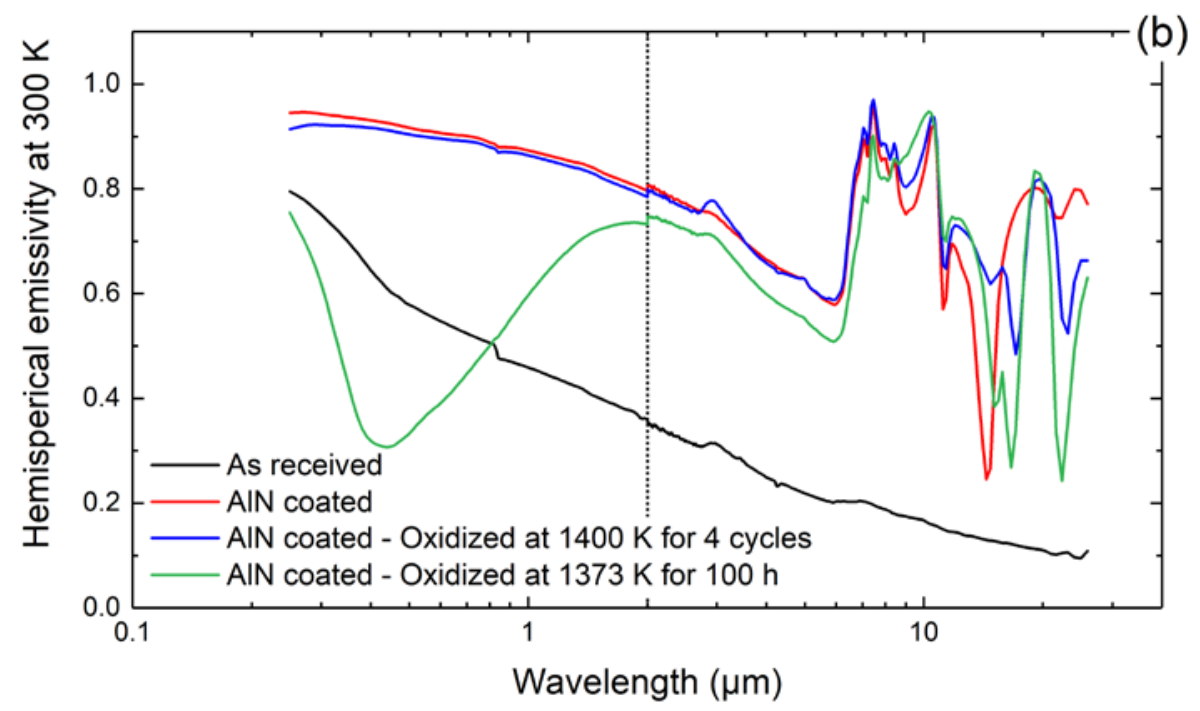

Figure 11: Hemispherical spectral emissivity of APMT and APMT + AIN as received, after cyclic oxidations in the REHTPS set-up and after $100 \mathrm{~h}$ oxidation in a furnace.

Table 3: Calculated values (from eq. (2) and (3) ) of the solar absorptivity, total emissivity and $\alpha / \varepsilon$ ratio for the as-received APMTand APMT + AIN as-received, after cyclic oxidation in the REHPTS setup and after $100 \mathrm{~h}$ oxidation in a muffle furnace.

\begin{tabular}{llll} 
& $\boldsymbol{\alpha}_{\text {sol }}$ & $\boldsymbol{\varepsilon}_{\text {tot }}$ & $\boldsymbol{\alpha} / \boldsymbol{\varepsilon}$ \\
\hline APMT, as received & 0.51 & 0.15 & 3.4 \\
APMT + AIN, as received & 0.89 & 0.71 & 1.2 \\
APMT + AIN, after cyclic oxidation at 1373 K & 0.88 & 0.73 & 1.2 \\
APMT + AIN, after 100h oxidation in a furnace at 1373 K & & & \\
(13) & 0.49 & 0.67 & 0.7
\end{tabular}

The optical properties of APMT are slightly higher than the ones of the FeCrAlloy. Consequently, the total emissivity of the AIN-coated APMT is higher than the one of the AIN-coated FeCrAlloy (0.71 vs. 0.62, respectively). The optical properties of the AIN-coated APMT are less affected by the cyclic oxidation than the ones of the AIN-coated Fecralloy. This is due to the fact the cyclic oxidation of AINcoated APMT was performed at slightly lower temperature than that of AIN-coated Fecralloy (1373 vs. $1490 \mathrm{~K}$ ) leading to a thinner oxide layer (Figure 7). This observation is confirmed by the fact that, after $100 \mathrm{~h}$ of exposure in air at $1373 \mathrm{~K}$, the solar absorptivity of the AIN-coated APMT is reduced to 0.49 , due to the transformation of the AIN into a non-optically selective layer of alumina.

\subsubsection{Conclusions}

AIN coatings on high temperature iron-based alloys have been extensively characterized from the point of view of oxidation, durability and optical properties. In the 1073-1173 K temperature range, very thin 
oxide scales mainly composed of alumina are grown. The lifetime of $40 \mu \mathrm{m}$ coatings can be several years. For a temperature of $1373 \mathrm{~K}$, the lifetime of the coating depends on its thickness, about $500 \mathrm{~h}$ for a $40 \mu \mathrm{m}$ coating. The measurement of the optical properties of the stack AIN/FeCrAl alloys showed a significant solar absorptivity in the solar spectrum and a $\alpha / \varepsilon$ ratio close to 1 . However, the development of the alumina scale leads to a decrease of the absorptivity. New measurements of optical and thermal properties, as well as durability at high temperature are needed to complete the evaluation of this coating. This coating is not the ideal material for CSP receivers working in air at temperature higher than $1273 \mathrm{~K}$. However, it is an efficient barrier on metals for the deposition of others ceramic coatings like SiC on high temperature alloys. Our recent results showed that oxidationresistant $\mathrm{AIN} / \mathrm{SiC}$ stacks are leading to higher absorptivity. They are worth investigating for receivers able to meet the requirements of the future CSP power plants for durability and performance.

\section{AKNOWLEDGEMENTS}

The authors want to thank the Agence Nationale de la Recherche (National Agency for Research) of the French State under awardsANR-16-CE08-0019 2MAC-CSP for supporting the development of this study. The authors also want to thank the program "Investissements d'Avenir" (Investment for the Future) of the Agence Nationale de la Recherche (National Agency for Research) of the French State under awards numbers ANR-10-LABX-22-01-SOLSTICE and ANR-10-EQPX-49-SOCRATE for supporting solar experimental facilities.

\section{REFERENCES}

[1]. Siefert, J. A.; Libby, C.; Shingledecker, J., Concentrating solar power (CSP) power cycle improvements through application of advanced materials. 2016, 1734, 070030.

[2]. Morris, D. G.; López-Delgado, A.; Padilla, I.; Muñoz-Morris, M. A., Selection of high temperature materials for concentrated solar power systems: Property maps and experiments. Solar Energy 2015, $112,246-258$

[3]. Ho, C. K.; Mahoney, A. R.; Ambrosini, A.; Bencomo, A.; Hall, A.; Lambert, T. N., Characterization of Pyromark 2500 Paint for High-Temperature Solar Receivers. Journal of Solar Energy Engineering 2014, 136, 014502.

[4]. Moon, J.; Lu, D.; VanSaders, B.; Kim, T. K.; Kong, S. D.; Jin, S.; Chen, R.; Liu, Z., High performance multi-scaled nanostructured spectrally selective coating for concentrating solar power. Nano Energy 2014, 8, 238-246.

[5]. Ávila-Marín, A. L., Volumetric receivers in Solar Thermal Power Plants with Central Receiver System technology: A review. Solar Energy 2011, 85 (5), 891-910.

[6]. Mey, S.; Caliot, C.; Flamant, G.; Kribus, A.; Gray, Y., Optimization of High Temperature SiC Volumetric Solar Absorber. Energy Procedia 2014, 49, 478-487.

[7]. Karas, D. E.; Byun, J.; Moon, J.; Jose, C., Copper-oxide spinel absorber coatings for hightemperature concentrated solar power systems. Solar Energy Materials and Solar Cells 2018, 182, 321330.

[8]. Boubault, A.; Claudet, B.; Faugeroux, O.; Olalde, G., Aging of solar absorber materials under highly concentrated solar fluxes. Solar Energy Materials and Solar Cells 2014, 123, 211-219.

[9]. Behar, O.; Khellaf, A.; Mohammedi, K., A review of studies on central receiver solar thermal power plants. Renewable and Sustainable Energy Reviews 2013, 23, 12-39.

[10]. Gray, M. H.; Tirawat, R.; Kessinger, K. A.; Ndione, P. F., High Temperature Performance of Highefficiency, Multi-layer Solar Selective Coatings for Tower Applications. Energy Procedia 2015, 69, 398404.

[11]. Yeh, C.-T.; Tuan, W.-H., Oxidation mechanism of aluminum nitride revisited. Journal of Advanced Ceramics 2017, 6 (1), 27-32. 
[12]. Korbutowicz, R.; Zakrzewski, A., Preliminary comparison of three processes of AIN oxidation: dry, wet and mixed ones. Materials Science-Poland 2016, 34 (1).

[13]. Ren, P.; Zhu, S.; Wang, F., TEM study of the evolution of sputtered Ni+CrAlYSiHfN nanocomposite coating with an AIN diffusion barrier at high temperature. Surface and Coatings Technology 2016, 286, 262-267.

[14]. Zhang, G.-H.; Hou, X.-M.; Chou, K.-C., Kinetics of non-isothermal oxidation of AIN powder. Journal of the European Ceramic Society 2010, 30 (2), 629-633.

[15]. Lin, C.-Y.; Lu, F.-H., Oxidation behavior of AIN films at high temperature under controlled atmosphere. Journal of the European Ceramic Society 2008, 28 (3), 691-698.

[16]. Casaux, Y.; Dollet, A.; Sibieude, F.; Berjoan, R., Influence de l'orientation cristalline sur la résistance à l'oxydation de revêtements de AIN : étude in-situ par diffractométrie X. Le Journal de Physique IV 1998, 08 (PR5), Pr5-249-Pr5-256.

[17]. Azema, N.; Durand, J.; Berjoan, R.; Dupuy, C.; Cot, L., Oxidation Stages of Aluminium Nitride Thin Films Obtained by Plasma-enhanced Chemical Vapour Deposition (PECVD). Journal of the European Ceramic Society 1991, 8, 291-298.

[18]. Ulrich, A. S.; Galetz, M. C. In Improving the oxidation resistance of refractory metals via aluminum diffusion coatings and halogen effect, Beyond Nickel-Based Superalloys II, Stone, H. J.; Bewlay, B. P.; Cornish, L. A., Eds. University of the Witwatersrand, South Africa: 2016.

[19]. Seiler, P.; Bäker, M.; Rösler, J., Influence of creep and cyclic oxidation in thermal barrier coatings. International Journal of Materials Research 2012, 103 (1), 50-56.

[20]. Mortazavi, N.; Geers, C.; Esmaily, M.; Babic, V.; Sattari, M.; Lindgren, K.; Malmberg, P.; Jonsson, B.; Halvarsson, M.; Svensson, J. E.; Panas, I.; Johansson, L. G., Interplay of water and reactive elements in oxidation of alumina-forming alloys. Nature Materials 2018, 17, 610-617.

[21]. Naumenko, D.; Pint, B. A.; Quadakkers, W. J., Current Thoughts on Reactive Element Effects in Alumina-Forming Systems: In Memory of John Stringer. Oxidation of Metals 2016, 86 (1-2), 1-43.

[22]. Dryepondt, S.; Turan, J.; Leonard, D.; Pint, B. A., Long-Term Oxidation Testing and Lifetime Modeling of Cast and ODS FeCrAl Alloys. Oxidation of Metals 2016, 87 (1-2), 215-248.

[23]. Jönsson, B.; Lu, Q.; Chandrasekaran, D.; Berglund, R.; Rave, F., Oxidation and Creep Limited Lifetime of Kanthal APMT ${ }^{\circledR}$, a Dispersion Strengthened FeCrAlMo Alloy Designed for Strength and Oxidation Resistance at High Temperatures. Oxidation of Metals 2013, 79 (1-2), 29-39.

[24]. Houngniou, C.; Chevalier, S.; Larpin, J. P., High-Temperature-Oxidation Behavior of IronAluminide Diffusion Coatings. Oxidation of Metals 2006, 65 (5-6), 409-439.

[25]. Berthomé, G.; N'Dah, E.; Wouters, Y.; Galerie, A., Temperature dependence of metastable alumina formation during thermal oxidation of FeCrAl foils. Materials and Corrosion 2005, 56 (6), 389392.

[26]. Buscail, H.; Perrier, S.; Josse, C., Oxidation mechanism of the Inconel 601 alloy at high temperatures. Materials and Corrosion 2011, 62 (5), 416-422.

[27]. Charpentier, L.; Caliot, C., The impact of the oxidation on the optical properties of TaC. Solar Energy Materials and Solar Cells 2017, 171, 16-23.

[28]. Boichot, R.; Coudurier, N.; Mercier, F.; Claudel, A.; Baccar, N.; Milet, A.; Blanquet, E.; Pons, M., CFD modeling of the high-temperature HVPE growth of aluminum nitride layers on c-plane sapphire: from theoretical chemistry to process evaluation. Theoretical Chemistry Accounts 2014, 133, 1419.

[29]. Boichot, R.; Coudurier, N.; Mercier, F.; Lay, S.; Crisci, A.; Coindeau, S.; Claudel, A.; Blanquet, E.; Pons, M., Epitaxial growth of AIN on c-plane sapphire by High Temperature Hydride Vapor Phase Epitaxy: Influence of the gas phase N/Al ratio and low temperature protective layer. Surface and Coatings Technology 2013, 237, 118-125.

[30]. Pons, M.; Boichot, R.; Coudurier, N.; Claudel, A.; Blanquet, E.; Lay, S.; Mercier, F.; Pique, D., High temperature chemical vapor deposition of aluminum nitride, growth and evaluation. Surface and Coatings Technology 2013, 230, 111-118.

[31]. Balaji, M.; Claudel, A.; Fellmann, V.; Gélard, I.; Blanquet, E.; Boichot, R.; Pierret, A.; AttalTrétout, B.; Crisci, A.; Coindeau, S.; Roussel, H.; Pique, D.; Baskar, K.; Pons, M., Effects of AIN nucleation 
layers on the growth of AIN films using high temperature hydride vapor phase epitaxy. Journal of Alloys and Compounds 2012, 526, 103-109.

[32]. Boichot, R.; Claudel, A.; Baccar, N.; Milet, A.; Blanquet, E.; Pons, M., Epitaxial and polycrystalline growth of AIN by high temperature CVD: Experimental results and simulation. Surface and Coatings Technology 2010, 205 (5), 1294-1301.

[33]. Charpentier, L.; Balat-Pichelin, M.; Sciti, D.; Silvestroni, L., High temperature oxidation of Zrand Hf-carbides: Influence of matrix and sintering additive. Journal of the European Ceramic Society 2013, 33 (15-16), 2867-2878.

[34]. Reference Solar Spectral Irradiance: Air Mass 1.5. American Society for Testing and Materials (ASTM) http://rredc.nrel.gov/solar/spectra/am1.5/.

[35]. Claudel, A.; Blanquet, E.; Chaussende, D.; Boichot, R.; Martin, R.; Mank, H.; Crisci, A.; Doisneau, B.; Chaudouet, P.; Coindeau, S.; Pique, D.; Pons, M., Growth and Characterization of Thick Polycrystalline AIN Layers by HTCVD. Journal of The Electrochemical Society 2011, 158 (3), H328.

[36]. Petrov, I.; Barna, P. B.; Hultman, L.; Greene, J. E., Microstructural evolution during film growth. Journal of Vacuum Science \& Technology A: Vacuum, Surfaces, and Films 2003, 21 (5), S117-S128.

[37]. Lee, J. W.; Radu, I.; Alexe, M., Oxidation behaviour of AIN substrate at low temperature. Journal of Materials Science: Materials in Electronics 2002, 13, 131-137.

[38]. Brown, A. L.; Norton, M. G., Oxidation kinetics of AIN powder. Journal of Materials Science Letters 1998, 17, 1519-1522.

[39]. Naumenko, D.; Gleeson, B.; Wessel, E.; Singheiser, L.; Quadakkers, W. J., Correlation between the Microstructure, Growth Mechanism, and Growth Kinetics of Alumina Scales on a FeCrAlY Alloy. Metallurgical and Materials Transactions A 2007, 38 (12), 2974-2983.

[40]. Wang, F.; Zhang, R.; Q.Xiu, X.; Lu, D. Q.; Gu, S. L.; Shen, B.; Shi, Y.; Zheng, Y. D., Study of Dry Oxidation of Aluminum Nitride on Si(111) Substrate Grown by Metalorganic Chemical Vapor Deposition. Surface Review and Letters 2003, 10 (4), 625-628.

[41]. Chowdhury, E. A.; Kolodzey, J.; Olowolafe, J. O.; Qiu, G.; Katulka, G.; Hits, D.; Dashiell, M.; van der Weide, D.; Swann, C. P.; Unruh, K. M., Thermally oxidized AIN thin films for device insulators. Applied Physics Letters 1997, 70 (20), 2732.

[42]. Ansart, F.; Ganda, H.; Saporte, R.; Traverse, J. P., Study of the oxidation of aluminium nitride coatings at high tempertaure. Thin Solid Films 1995, 260, 38-46.

[43]. Labatut, C.; Kharchi, D.; Aspar, B.; Sibieude, F.; Armas, B., An In-situ Fabricated Study of the Oxidation of A1N Layers by LPCVD Using X-Ray Diffraction. Journal of The European Ceramic Society 1994, 13, 119-344.

[44]. Hou, X. M.; Chou, K. C., Quantitative interpretation of the parabolic and nonparabolic oxidation behavior of nitride ceramic. Journal of the European Ceramic Society 2009, 29 (3), 517-523.

[45]. Ren, P.; Zhu, S.; Wang, F., Microstructure and oxidation behavior of a Ni+CrAlYSiHfN/AIN multilayer coating fabricated by reactive magnetron sputtering. Corrosion Science 2016, 104, 197-206. [46]. Smialek, J. L.; Jacobson, N. S.; Gleason, B.; Hovis, D. B.; Heuer, A. H. Oxygen Permeability and Grain-Boundary Diffusion Applied to Alumina Scales; Nasa Center for Aerospace Information: 2013.

[47]. Korbutowicz, R.; Zakrzewski, A.; Rac-Rumijowska, O.; Stafiniak, A.; Vincze, A., Oxidation rates of aluminium nitride thin films: effect of composition of the atmosphere. Journal of Materials Science: Materials in Electronics 2017, 28 (18), 13937-13949.

[48]. Yeh, C.-T.; Tuan, W.-H., Accelerating the oxidation rate of AIN substrate through the addition of water vapor. Journal of Asian Ceramic Societies 2017, 5 (4), 381-384.

[49]. Yeh, C.-T.; Tuan, W.-H., Pre-oxidation of AIN substrates for subsequent metallization. Journal of Materials Science: Materials in Electronics 2015, 26 (8), 5910-5916. 